\title{
Electronic cigarette exposures reported to the British Columbia Drug and Poison Information Centre: an observational case series
}

\author{
Alex Choi MD MHSc, Megan Le MD, Tissa Rahim MSc, Caren Rose PhD, Tom Kosatsky MD MPH
}

Abstract

Background: Electronic nicotine delivery systems (ENDSs), including electronic cigarettes (e-cigarettes), are rapidly gaining popularity. The aim of this study was to use poison centre data to describe epidemiological trends in ENDS-related exposures.

Methods: We conducted an observational case series study using records containing both coded fields and free-text narratives from the British Columbia Drug and Poison Information Centre for all calls involving exposure to ENDS received from 2012 to 2017. We described trends in exposures and exposed people, as well as clinical effects.

Results: A total of 243 calls were recorded for 186 unique exposures to ENDS devices, e-juice, e-cigarette cartridges and other associated paraphernalia over the study period. Calls related to ENDS exposures increased nearly sixfold between 2013 and 2014 and did not decline subsequently. Exposures were most frequently documented in children aged 4 years or less (81 [43.5\%]), with 58 $(31.0 \%)$ in 1- and 2-year-olds. Seventy-two exposures (89\%) in children aged 4 years or less were due to accidental ingestion, whereas adults aged 25 years or more called the poison centre following ENDS malfunctions (7 [23\%], spills (4 [13\%]) and exposure to e-juice mistaken for other substances (4 [13\%]). Of the 186 exposed people, $87(46.8 \%)$ reported symptoms.

Interpretation: British Columbia experienced a sixfold increase in ENDS-related calls to the provincial poison centre between 2012 and 2017, driven by ingestions in young children. Regulatory approaches aimed at minimizing children's access to ENDS, clear labelling of nicotine concentration, and packaging that reduces the likelihood of spills, product confusion and malfunction should be considered.

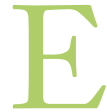
lectronic nicotine delivery systems (ENDSs), including electronic cigarettes (e-cigarettes), were first introduced to North American markets in 2007. They are designed to vaporize inhalable chemical combinations for an experience that mimics smoking. ${ }^{1}$ Devices typically include an electronic heating and aerosolization system and a cartridge of "e-juice" or "e-liquid," a variable mixture of propylene glycol (a carrier compound), glycerol, nicotine and flavouring. ${ }^{2}$ Although the overall prevalence of traditional cigarette smoking has been declining, ENDS use is increasing, particularly among middle and high school students, the first increase in nicotine product use in decades. ${ }^{3-8}$

In the United States, the National Poison Data System uses near-real-time data from 55 poison control centres for monitoring and surveillance. Poison centres in that country have reported increases in the frequency of ENDS-related calls. ${ }^{9-12}$ Although most calls involve minimal toxic effects, ${ }^{11,13}$ case reports have documented severe neurologic symptoms, anoxic brain injury and death resulting from unintentional pediatric ingestion of e-juice. ${ }^{14,15}$ The primary known hazard associated with ENDS exposure is nicotine, which is absorbed through the skin, alveoli and oropharyngeal/gastrointestinal mucosa. ${ }^{14}$ Although nicotine is most commonly associated with central nervous system excitation, excessive or prolonged exposure can result in loss of receptor specificity and paradoxical inhibition, causing cholinergic toxicity and blockade at the neuromuscular junction. The lethal adult dosage of nicotine is estimated at less than $1 \mathrm{mg} / \mathrm{kg} .{ }^{14}$ Many ENDSs (including "nicotine-free" formulations) contain nicotine in excess of their labelled concentrations. ${ }^{16-19} \mathrm{We}$ examined all ENDSrelated calls to British Columbia's poison centre, exploring trends in exposures, those exposed, causes of exposures and clinical outcomes within a rapidly changing use environment and the Canadian context.

\section{Competing interests: None declared.}

This article has been peer reviewed.

Correspondence to: Alex Choi, alexandra.h.choi@gmail.com

CMAJ Open 2019. DOI:10.9778/cmajo.20180203 


\section{Methods}

\section{Data sources}

The British Columbia Drug and Poison Information Centre (DPIC) provides toll-free poison information and treatment recommendations to the general public and health care professionals of British Columbia (population 4.8 million) 24 hours a day, 7 days a week. ${ }^{20,21}$ The DPIC pharmacists and nurses, who are trained on site, certified by the American Association of Poison Control Centers and supported by medical toxicologists, consult on over 26000 calls each year. ${ }^{22}$ The public can call the DPIC directly or be transferred to the DPIC should they call HealthLink BC about exposure to a potentially dangerous substance or medication. Group homes, emergency medical technicians and clinicians call the DPIC for assistance in managing poisonings. In cases in which the exposed person can be managed at home, the DPIC requests or initiates follow-up until the person's condition is stable and, if the person is advised to seek further treatment, collects information on clinical outcome.

Product information is entered with the use of American Association of Poison Control Centers generic codes and product codes, and Poisindex (IBM Corporation) descriptors. All data are maintained in an electronic database. We reviewed all e-cigarette and ENDS-related calls received between Jan. 1, 2012, and Dec. 31, 2017 coded as American Association of Poison Control Centers 200620: electronic cigarettes: device containing nicotine without added flavours; 200622: electronic cigarettes: nicotine device with added flavours; 310095: electronic cigarettes: nicotine liquid flavor unknown; or 310094: electronic cigarettes: nicotine device flavour unknown.

\section{Design}

We captured all exposure-related calls, regardless of toxic effects, clinical symptoms or outcomes. Some exposures led to multiple calls, and some callbacks were initiated by the DPIC. To avoid double counting, we counted multiple calls regarding a single exposure once, although information was extracted from the entire longitudinal call record. Exposures involving multiple coingested substances were included in all analyses except those describing symptoms and care trajectory, since ENDS-attributable symptoms could not be reliably disaggregated. Nonhuman exposures and callers purely seeking information were excluded.

We obtained the call records containing coded fields and free-text narratives for all ENDS-related calls. Two coauthors (A.C. and M.L.) reviewed the free-text narratives and verified all coded fields (Appendix 1, available at www.cmajopen.ca/ content/7/3/E462/suppl/DC1). Coded fields that were assessed included the age and gender of the exposed person, relationship to the caller, route of exposure, location of exposure, coingested substances and timing of both the call and the exposure.

We abstracted additional data from the free-text narrative into predetermined standardized fields. We reviewed the freetext narrative to assess the vehicle of exposure (e.g., ENDS device, e-cigarette cartridge, e-juice or e-liquid), source (self, household member, other person, workplace, found object), cause (e.g., accidental access, device malfunction, usual use, misuse) and clinical symptoms. In cases in which the flavour, nicotine content, nicotine concentration and/or dosage appeared in the coded fields or the free-text narrative, it was recorded.

In keeping with the biphasic pattern typical of toxic nicotine effects, we classified symptoms as stimulatory or depressive. Calls in which nausea, vomiting, headache, dizziness, anxiety and/or tachycardia were noted were coded as "stimulatory effects typical of low-level nicotine exposure," $23-25$ and calls in which seizure, coma and/or respiratory failure were reported were coded as "depressive effects typical of high-level nicotine exposure." $23,26,27$ If both stimulatory and depressive effects were reported, both were recorded. In cases in which only symptoms other than those listed above were noted, we applied the code "not typical of exposure to nicotine."

We extracted the number of patient callbacks and the interval between the recorded time of exposure and the last contact with the DPIC from the free-text record. The clinical trajectory (managed at the caller's site, assessed at a health care facility or admitted) was abstracted from the standardized fields.

To assess whether calls were received in proportion to where BC residents live, we allocated callers to BC's 16 Health Service Delivery Areas. ${ }^{28} \mathrm{We}$ also categorized the exposed person's place of residence (which is routinely recorded) as metropolitan, mixed urban/rural or remote using the BC Ministry of Health's geographic service area definitions. ${ }^{29}$

\section{Statistical analysis}

We described characteristics of ENDS exposures and exposed people using frequencies and proportions. These were stratified by age, route of exposure and nicotine concentration. We compared age, gender and geographic area to those of the BC population using the $\chi^{2}$ test. We assessed trends for the presence or absence of symptoms and care trajectory as a function of nicotine concentration at exposure using the CochranArmitage test.

\section{Ethics approval}

We consulted the BC Centre for Disease Control privacy officer, who advised that ethics approval was not required given that the data were depersonalized, nonidentifiable and used solely for the purposes of surveillance and quality assurance.

\section{Results}

\section{Characteristics of exposures and exposed people}

From 2012 to 2017, 243 calls were recorded for 186 unique exposures to ENDS devices, e-juice, e-cigarette cartridges and other associated paraphernalia, for a rate of 0.02 unique exposures/year per 100000 population. Calls regarding ENDS exposure were infrequent in 2012 and 2013; a nearly sixfold increase occurred in 2014, and the number of calls did not abate in subsequent years (Table 1). From 2014 to 2017, there was a mean of 43 (range 39-47) calls per year.

Of the 186 exposures, 108 (58.1\%) concerned males, and the median age was 3 years (range 1-75 yr). Exposures were 
most frequently reported in 1-year-olds (30 [16.1\%]), followed by 2 -year-olds (28 [15.1\%]) and infants less than 1 year (11 [5.9\%]). A small second peak was seen in adolescents aged 15-16 years (11 [5.9\%]) (Figure 1). The increase in calls over the study period was driven by exposures in young children (Figure 2).

Most exposures (175 [94.1\%]) occurred at the exposed person's place of residence, $6(3.2 \%)$ occurred in a public area, 2
(1.1\%) occurred at workplaces, and $1(0.5 \%)$ occurred in a school; the location was unknown for the remaining 2 exposures. Of the 72 exposed children aged 4 years or less for whom location was known, 68 (94\%) accessed an ENDS or ENDS paraphernalia in their own households.

People from rural and remote areas accounted for 41 $(22.0 \%)$ of the exposures but only $11.9 \%$ of the province's population. Three of the top 5 highest rates of regional

\begin{tabular}{|c|c|c|c|c|c|}
\hline \multirow[b]{2}{*}{ Characteristic } & \multicolumn{2}{|c|}{ No. $(\%)$ of people } & \multirow[b]{2}{*}{$\chi^{2}$} & \multirow[b]{2}{*}{$\begin{array}{l}\text { Degrees } \\
\text { of freedom }\end{array}$} & \multirow[b]{2}{*}{$p$ value } \\
\hline & $\begin{array}{l}\text { Exposures } \\
\text { reported to BC } \\
\text { poison centre } \\
n=186\end{array}$ & $\begin{array}{c}\text { BC population }{ }^{20,21} \\
n=4648060\end{array}$ & & & \\
\hline \multicolumn{6}{|c|}{ Demographic characteristics of exposed people } \\
\hline Gender & & & 6.9 & 1 & 0.009 \\
\hline Female & $76(40.9)$ & $2370000(51.0)$ & & & \\
\hline Male & $108(58.1)$ & $2279000(49.0)$ & & & \\
\hline Unknown* & $2(1.1)$ & - & & & \\
\hline Age, yr & & & 874.0 & 4 & $<0.001$ \\
\hline$\leq 4$ & $81(43.5)$ & $221000(4.8)$ & & & \\
\hline $5-14$ & $7(3.8)$ & $471000(10.1)$ & & & \\
\hline $15-19$ & $18(9.7)$ & $259000(5.6)$ & & & \\
\hline $20-24$ & $7(3.8)$ & $288000(6.2)$ & & & \\
\hline$\geq 25$ & $31(16.7)$ & $3410000(73.4)$ & & & \\
\hline Not recorded ${ }^{*}$ & $42(22.6)$ & - & & & \\
\hline \multicolumn{6}{|c|}{ Temporal and geographic characteristics of calls } \\
\hline Year & & - & & & \\
\hline 2012 & $7(3.8)$ & & & & \\
\hline 2013 & $7(3.8)$ & & & & \\
\hline 2014 & $39(21.0)$ & & & & \\
\hline 2015 & $47(25.3)$ & & & & \\
\hline 2016 & $40(21.5)$ & & & & \\
\hline 2017 & $46(24.7)$ & & & & \\
\hline Time of day & & - & & & \\
\hline 0600-1159 & $31(16.7)$ & & & & \\
\hline $1200-1759$ & $71(38.2)$ & & & & \\
\hline $1800-2359$ & $72(38.7)$ & & & & \\
\hline 0000-0559 & $12(6.4)$ & & & & \\
\hline Geographic area & & & 30.6 & 2 & $<0.001$ \\
\hline Metropolitan & $77(41.4)$ & $2643866(56.4) \dagger$ & & & \\
\hline Mixed urban/rural & $62(33.3)$ & $1485317(31.7) \dagger$ & & & \\
\hline Rural/remote & $41(22.0)$ & $561395(12.0) \dagger$ & & & \\
\hline Not recorded* & $6(3.2)$ & - & & & \\
\hline
\end{tabular}


ENDS exposure were geographically clustered in Vancouver Island's 3 Health Service Delivery Areas, 1 of which had the highest rate of reported exposures in the province (8.5/ 100000 residents).

\section{Exposures and clinical sequelae}

Exposure characteristics by age are presented in Table 2. Exposures in children less than age 5 years were almost always the result of accidental access to (77 [95\%]) and ingestion of

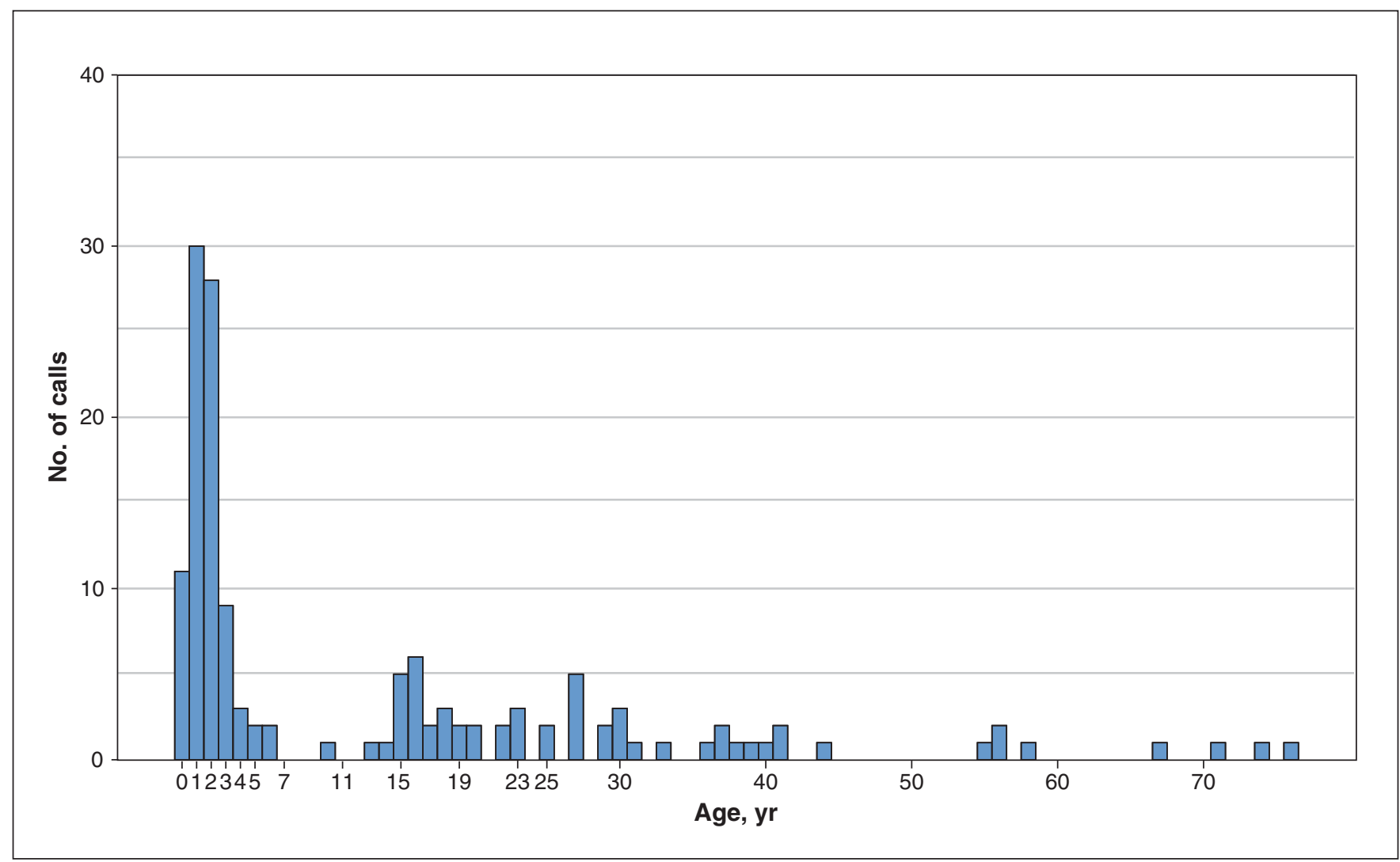

Figure 1: Frequency of unique exposure calls to the British Columbia Drug and Poison Information Centre for exposure to electronic nicotine delivery systems by age, 2012-2017.

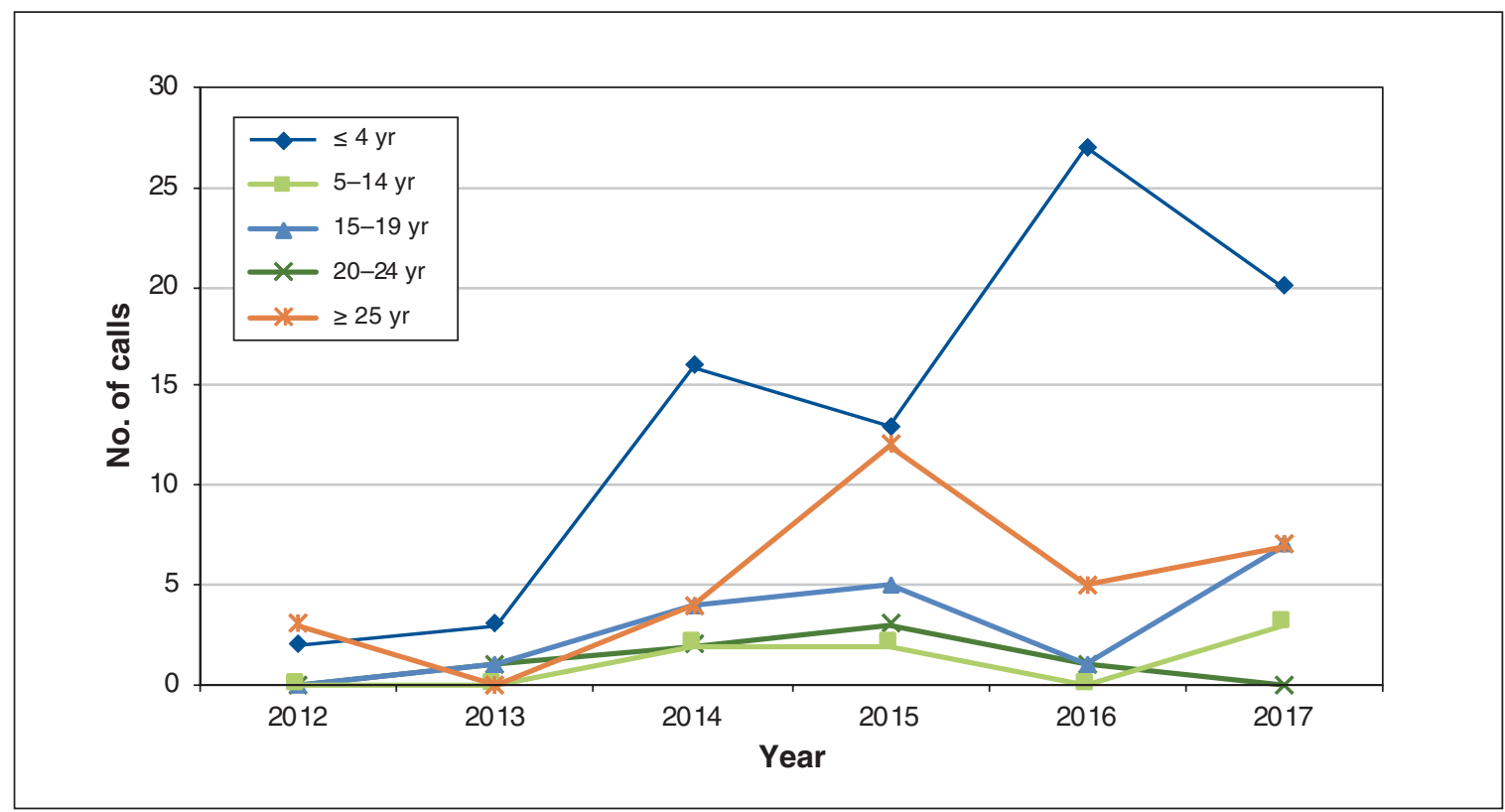

Figure 2: Frequency of unique exposure calls to the British Columbia Drug and Poison Information Centre for exposure to electronic nicotine delivery systems by age group and year. 
(43 [53\%]) bottled e-juice. Adults aged 25 years or more called the poison centre following spills in 4 cases (13\%), ENDS malfunction in 7 (23\%) and mistaking e-juices for other substances such as eyedrops in 4 (13\%). Four exposures were coded as chronic, defined as "continuous, repeated, or intermittent" and lasting more than 8 hours. ${ }^{30}$

\section{Table 2: Characteristics of exposures to electronic nicotine delivery systems, symptoms and care trajectories, by age group}

\begin{tabular}{|c|c|c|c|c|c|c|c|}
\hline \multirow[b]{2}{*}{ Characteristic } & \multicolumn{7}{|c|}{ Age group, yr; no. (\%) of people } \\
\hline & $\begin{array}{c}\leq 4 \\
n=81\end{array}$ & $\begin{array}{l}5-14 \\
n=7\end{array}$ & $\begin{array}{l}15-19 \\
n=18\end{array}$ & $\begin{array}{c}20-24 \\
n=7\end{array}$ & $\begin{array}{c}\geq 25 \\
n=31\end{array}$ & $\begin{array}{c}\text { Unknown } \\
n=42\end{array}$ & $\begin{array}{c}\text { Total } \\
n=186\end{array}$ \\
\hline \multicolumn{8}{|l|}{ Cause of exposure } \\
\hline Accidental access ${ }^{*}$ & $77(95)$ & $4(57)$ & $2(11)$ & $0(0)$ & $0(0)$ & $2(5)$ & $85(45.7)$ \\
\hline Handling device† & $0(0)$ & $1(14)$ & $3(17)$ & $1(14)$ & $1(3)$ & $4(10)$ & $10(5.4)$ \\
\hline Intentional inappropriate use & $0(0)$ & $1(14)$ & $1(6)$ & $1(14)$ & $2(6)$ & $2(5)$ & $7(3.8)$ \\
\hline Making e-juice & $0(0)$ & $0(0)$ & $0(0)$ & $0(0)$ & $1(3)$ & $0(0)$ & $1(0.5)$ \\
\hline E-cigarette malfunction & $1(1)$ & $0(0)$ & $2(11)$ & $0(0)$ & $7(23)$ & $7(17)$ & $17(9.1)$ \\
\hline Mistaken identity $\ddagger$ & $1(1)$ & $0(0)$ & $0(0)$ & $1(14)$ & $4(13)$ & $6(14)$ & $12(6.4)$ \\
\hline Spill & $1(1)$ & $0(0)$ & $1(6)$ & $2(29)$ & $4(13)$ & $5(12)$ & $13(7.0)$ \\
\hline Usual e-cigarette use & $0(0)$ & $0(0)$ & 7 (39) & $1(14)$ & $10(32)$ & $7(17)$ & $25(13.4)$ \\
\hline Other/not recorded & $1(1)$ & $1(14)$ & $2(11)$ & $1(14)$ & $2(6)$ & $9(21)$ & $16(8.6)$ \\
\hline \multicolumn{8}{|l|}{ Vehicle of exposure } \\
\hline E-cigarette device & $19(23)$ & $0(0)$ & $12(67)$ & $3(43)$ & $19(61)$ & $21(50)$ & $74(39.8)$ \\
\hline E-cigarette cartridge & $11(14)$ & $1(14)$ & $1(6)$ & $1(14)$ & $1(3)$ & $2(5)$ & $17(9.1)$ \\
\hline Bottled e-juice & $50(62)$ & $6(86)$ & $5(28)$ & $3(43)$ & $11(35)$ & $18(43)$ & $93(50.0)$ \\
\hline Other/not recorded & $1(1)$ & $0(0)$ & $0(0)$ & $0(0)$ & $0(0)$ & $1(2)$ & $2(1.1)$ \\
\hline \multicolumn{8}{|l|}{ Route of exposure§ } \\
\hline Dermal & $6(7)$ & $1(14)$ & $2(11)$ & $2(29)$ & $4(13)$ & $7(17)$ & $22(11.8)$ \\
\hline Ingestion & 72 (89) & $6(86)$ & $8(44)$ & $4(57)$ & $14(45)$ & $18(43)$ & $122(65.6)$ \\
\hline Inhalation & $2(2)$ & $0(0)$ & $8(44)$ & $1(14)$ & $10(32)$ & $7(17)$ & $28(15.0)$ \\
\hline Nasal & $0(0)$ & $0(0)$ & $0(0)$ & $0(0)$ & $1(3)$ & $0(0)$ & $1(0.5)$ \\
\hline Ocular & $1(1)$ & $0(0)$ & $0(0)$ & $0(0)$ & $2(6)$ & $9(21)$ & $12(6.4)$ \\
\hline Vaginal & $0(0)$ & $0(0)$ & $0(0)$ & $0(0)$ & $0(0)$ & $1(2)$ & $1(0.5)$ \\
\hline \multicolumn{8}{|l|}{ Symptoms presentף } \\
\hline Yes & $9(11)$ & $3(43)$ & $16(89)$ & $4(57)$ & $27(87)$ & $28(67)$ & $87(46.8)$ \\
\hline No & $54(67)$ & $4(57)$ & $1(6)$ & $2(29)$ & $2(6)$ & $7(17)$ & $70(37.6)$ \\
\hline Not recorded & $18(22)$ & $0(0)$ & $1(6)$ & $1(14)$ & $2(6)$ & $7(17)$ & $29(15.6)$ \\
\hline \multicolumn{8}{|l|}{ Care trajectory } \\
\hline $\begin{array}{l}\text { Managed outside of health } \\
\text { care facility }{ }^{\star *}\end{array}$ & $50(62)$ & $6(86)$ & $12(67)$ & $6(86)$ & $24(77)$ & $33(79)$ & $131(70.4)$ \\
\hline $\begin{array}{l}\text { Treated/evaluated at health } \\
\text { care facility and released }\end{array}$ & $22(27)$ & $0(0)$ & $2(11)$ & $0(0)$ & $5(16)$ & $3(7)$ & $32(17.2)$ \\
\hline $\begin{array}{l}\text { Admitted to noncritical care } \\
\text { unit }\end{array}$ & $2(2)$ & $1(14)$ & $2(11)$ & $1(14)$ & $1(3)$ & $1(2)$ & $8(4.3)$ \\
\hline Admitted to critical care unit & $1(1)$ & $0(0)$ & $0(0)$ & $0(0)$ & $0(0)$ & $0(0)$ & $1(0.5)$ \\
\hline Lost to follow-up & $6(7)$ & $0(0)$ & $2(11)$ & $0(0)$ & $1(3)$ & $5(12)$ & $14(7.5)$ \\
\hline \multicolumn{8}{|c|}{$\begin{array}{l}\text { Note: e-cigarette = electronic cigarette. } \\
\text { *Accidental acquisition of electronic nicotine delivery system or associated paraphernalia by a person (usually a child) who is not the intended user and subsequent use } \\
\text { without the intention of causing harm. } \\
\text { †Includes cleaning, refilling or otherwise manipulating electronic nicotine delivery system and cartridges. } \\
\text { fE-juice mistaken for another substance (e.g., eyedrops), frequently housed in a similar container. } \\
\text { §Cases with multiple routes of exposure were counted in all applicable categories. } \\
\text { १Excludes coingestions as these substances may have contributed to symptomatology. } \\
\star{ }^{\star} \text { Includes during emergency transportation. }\end{array}$} \\
\hline
\end{tabular}


Nine people identified a second exposure that may have contributed to the clinical picture. Of the 9, 2 were exposed to a second nicotine-containing substance, 2 had recently undergone a change in psychotropic medications, 1 was exposed to alcohol (and potentially $\gamma$-hydroxybutyric acid), 1 was exposed to tetrahydrocannabinol, 1 was exposed to gun oil, and 1 was exposed to analgesics, possibly including opioids; the remaining person was exposed to acetaminophen and acetaminophen plus codeine. There were no calls about second-hand exposure to ENDS vapours.

Nearly half (87 [46.8\%]) of those exposed reported symptoms. Although only 9 children $(11 \%)$ aged 4 years or less were documented to be symptomatic, 25 (31\%) were seen at health care facilities. In contrast, $16(89 \%)$ of those aged $15-19$ were symptomatic, but only 4 (22\%) were seen at health care facilities (Table 2).

Ninety-seven callers $(52.2 \%)$ provided the labelled concentration of their ENDS products. Three $(75 \%)$ of the 4 exposed to "no-nicotine" solutions experienced symptoms, compared to 7 (39\%) of those exposed to low-level nicotine solutions, 15 (28\%) of those exposed to medium-level solutions, $6(40 \%)$ of those exposed to high-level solutions and 4 (57\%) of those exposed to solutions with very high nicotine levels (Table 3). Of the 87 cases in which symptoms were noted, 42 (48\%) were typical of low-level systemic nicotine exposure. Only 2 exposures (2\%), both ingestions, were associated with systemic symptoms compatible with high-level nicotine dosing (Table 4). The symptoms and care trajectories for the 49 exposures in children aged 4 years or less for which the nicotine concentration was available or could be estimated are presented in Table 5 .

Excluding chronic exposures, the median time between the exposure and the initial call to the poison centre was 10 minutes (range $0 \mathrm{~min}$ to $62 \mathrm{~d}$ ). Ninety-five callers $(51.1 \%$ ) telephoned the poison centre within 10 minutes, and $153(82.2 \%)$ within 60 minutes. The number of callbacks and the duration of contact with the poison centre were highest for those exposed to e-juice containing higher concentrations of nicotine (Table 6).

\section{Missing information and absent fields}

The volume of exposure was not specified in 130 call records (70.4\%). Product names and characteristics were recorded in less than 5 cases. A total of 119 call records $(64.0 \%)$ contained no mention of flavouring. Packaging attributes (e.g., childproof packaging) were not recorded.

\section{Interpretation}

The BC DPIC experienced an increase in calls regarding ENDS exposures between 2012 and 2017, predominantly

\begin{tabular}{|c|c|c|c|c|c|}
\hline \multirow[b]{2}{*}{ Variable } & \multicolumn{5}{|c|}{ Nicotine concentration, $\mathrm{mg} / \mathrm{mL}$; no. (\%) of people } \\
\hline & $\begin{array}{c}0 \\
n=4\end{array}$ & $\begin{array}{l}0.1-5 \\
n=18\end{array}$ & $\begin{array}{c}6-17 \\
n=53\end{array}$ & $\begin{array}{l}18-23 \\
n=15\end{array}$ & $\begin{array}{l}\geq 24 \\
n=7\end{array}$ \\
\hline \multicolumn{6}{|l|}{ Age group, yr } \\
\hline$\leq 4$ & $0(0)$ & $8(44)$ & $33(62)$ & $9(60)$ & $4(57)$ \\
\hline $5-14$ & $0(0)$ & $4(22)$ & $0(0)$ & $0(0)$ & $0(0)$ \\
\hline 15-19 & $1(25)$ & $1(6)$ & $6(11)$ & $0(0)$ & $1(14)$ \\
\hline $20-24$ & $0(0)$ & $1(6)$ & $2(4)$ & $1(7)$ & $0(0)$ \\
\hline$\geq 25$ & $1(25)$ & $2(11)$ & $7(13)$ & $3(20)$ & $1(14)$ \\
\hline Not recorded & $2(50)$ & $2(11)$ & $5(9)$ & $2(13)$ & $1(14)$ \\
\hline \multicolumn{6}{|l|}{ Symptoms present } \\
\hline Yes & $3(75)$ & 7 (39) & $15(28)$ & $6(40)$ & $4(57)$ \\
\hline No & $0(0)$ & $11(61)$ & $29(55)$ & $7(47)$ & $1(14)$ \\
\hline Not recorded & $1(25)$ & $0(0)$ & $9(17)$ & $2(13)$ & $2(29)$ \\
\hline \multicolumn{6}{|l|}{ Care trajectory } \\
\hline $\begin{array}{l}\text { Managed outside of health care } \\
\text { facility† }\end{array}$ & $3(75)$ & $13(72)$ & $37(70)$ & $11(73)$ & $5(71)$ \\
\hline $\begin{array}{l}\text { Treated/evaluated at health care } \\
\text { facility and released }\end{array}$ & $1(25)$ & $4(22)$ & $10(19)$ & $3(20)$ & $2(29)$ \\
\hline Admitted to noncritical care unit & $0(0)$ & $0(0)$ & $2(4)$ & $1(7)$ & $0(0)$ \\
\hline Lost to follow-up & $0(0)$ & $1(6$ & $4(8)$ & $0(0)$ & $0(0)$ \\
\hline
\end{tabular}


Table 4: Symptoms by route of exposure*

\begin{tabular}{|c|c|c|c|c|}
\hline \multirow[b]{2}{*}{ Variable } & \multicolumn{4}{|c|}{ Route; no. (\%) of people } \\
\hline & $\begin{array}{c}\text { Dermal† } \\
n=22\end{array}$ & $\begin{array}{c}\text { Ingestion } \dagger \\
n=122\end{array}$ & $\begin{array}{c}\text { Inhalation } \dagger \\
n=28\end{array}$ & $\begin{array}{c}\text { Total } \ddagger \\
n=186\end{array}$ \\
\hline \multicolumn{5}{|l|}{ Symptoms present } \\
\hline Yes & $12(54.5)$ & $38(31.1)$ & 25 (89.3) & $87(46.8)$ \\
\hline No & $7(31.8)$ & $60(49.2)$ & $2(7.1)$ & $70(37.6)$ \\
\hline Not recorded & $3(13.6)$ & $24(19.7)$ & $1(3.6)$ & $29(15.6)$ \\
\hline \multicolumn{5}{|l|}{ Symptoms§ } \\
\hline \multicolumn{5}{|l|}{ Local } \\
\hline Dermal & $4(18.2)$ & $0(0.0)$ & $1(3.6)$ & $5(2.7)$ \\
\hline Oral/pharyngeal & $0(0.0)$ & $7(5.7)$ & $1(3.6)$ & $9(4.8)$ \\
\hline Respiratory & $0(0.0)$ & $1(0.8)$ & $1(3.6)$ & $3(1.6)$ \\
\hline Ocular & $0(0.0)$ & $0(0.0)$ & $0(0.0)$ & $11(5.9)$ \\
\hline Vaginal & $0(0.0)$ & $0(0.0)$ & $0(0.0)$ & $1(0.5)$ \\
\hline \multicolumn{5}{|l|}{ Systemic } \\
\hline $\begin{array}{l}\text { Not typical for nicotine } \\
\text { exposure }\end{array}$ & $4(18.2)$ & $19(15.6)$ & $11(39.3)$ & $45(24.2)$ \\
\hline $\begin{array}{l}\text { Typical for low nicotine } \\
\text { exposure }\end{array}$ & $8(36.4)$ & $18(14.8)$ & $15(53.6)$ & $42(22.6)$ \\
\hline $\begin{array}{l}\text { Typical for high nicotine } \\
\text { exposure }\end{array}$ & $0(0.0)$ & $2(1.6)$ & $0(0.0)$ & $2(1.1)$ \\
\hline $\begin{array}{l}{ }^{*} \text { Excludes people with coingestio } \\
\text { †Excludes people with multiple } \\
\text { flncludes people with nasal, ocu } \\
\S \text { Some people experienced mult }\end{array}$ & $\begin{array}{l}\text { se substar } \\
\text { xposure. } \\
\text { aginal exp } \\
\text { toms. }\end{array}$ & $\begin{array}{l}\text { ve contribut } \\
\text { as multipl }\end{array}$ & $\begin{array}{l}\text { tomatology. } \\
\text { f exposure. }\end{array}$ & \\
\hline
\end{tabular}

\section{Table 5: Symptoms and care trajectories for the 49 exposures in children aged 4 years or less for which the nicotine concentration was available or could be estimated, by nicotine concentration of the product ingested}

\begin{tabular}{|c|c|c|c|c|}
\hline \multirow[b]{2}{*}{ Variable } & \multicolumn{4}{|c|}{ Nicotine concentration, mg/mL; no. (\%) of children* } \\
\hline & $\begin{array}{l}0.1-5 \\
n=7\end{array}$ & $\begin{array}{c}6-17 \\
n=30\end{array}$ & $\begin{array}{l}18-23 \\
n=11\end{array}$ & $\begin{array}{l}\geq 24 \\
n=1\end{array}$ \\
\hline \multicolumn{5}{|l|}{ Symptoms } \\
\hline Present & $0(0)$ & $1(3)$ & $3(27)$ & $0(0)$ \\
\hline Absent & $7(100)$ & $22(73)$ & $5(45)$ & $0(0)$ \\
\hline Not recorded & $0(0)$ & $7(23)$ & $3(27)$ & $1(100)$ \\
\hline \multicolumn{5}{|l|}{ Care trajectory $\ddagger$} \\
\hline $\begin{array}{l}\text { Managed outside health } \\
\text { care facility }\end{array}$ & $3(43)$ & $19(63)$ & $7(64)$ & $1(100)$ \\
\hline Seen at health care facility & $3(43)$ & $8(27)$ & $3(27)$ & $0(0)$ \\
\hline Admitted & $0(0)$ & $0(0)$ & $1(9)$ & $0(0)$ \\
\hline Lost to follow-up & $1(14)$ & $3(10)$ & $0(0)$ & $0(0)$ \\
\hline \multicolumn{5}{|c|}{$\begin{array}{l}{ }^{*} \text { Three children who ingested electronic cigarette products were admitted to hospital, but no product nicotine concentratio } \\
\text { was recorded. } \\
\text { †Cochran-Armitage test for trend }=7.73,2 \text { degrees of freedom, } p=0.02 \text {. } \\
\neq \text { Cochran-Armitage test for trend }=5.36,6 \text { degrees of freedom, } p=0.5 .\end{array}$} \\
\hline
\end{tabular}




\begin{tabular}{|c|c|c|c|c|}
\hline \multicolumn{5}{|c|}{$\begin{array}{l}\text { Table 6: Callbacks and duration of contact with } \mathrm{BC} \text { poison centre for children aged } \\
4 \text { years or less, by nicotine concentration of the electronic nicotine delivery system } \\
\text { product ingested* }\end{array}$} \\
\hline \multirow[b]{2}{*}{ Variable } & \multicolumn{4}{|c|}{ Nicotine concentration, $\mathrm{mg} / \mathrm{mL}$; no. (\%) of children } \\
\hline & $\begin{array}{l}0.1-5 \\
n=7\end{array}$ & $\begin{array}{c}6-17 \\
n=30\end{array}$ & $\begin{array}{l}18-23 \\
n=11\end{array}$ & $\begin{array}{l}\geq 24 \\
n=1\end{array}$ \\
\hline \multicolumn{5}{|l|}{ No. of callbacks } \\
\hline 0 & 5 & 11 & 2 & 0 \\
\hline 1 & 1 & 9 & 5 & 1 \\
\hline 2 & 1 & 7 & 2 & 0 \\
\hline 3 & 0 & 1 & 1 & 0 \\
\hline 4 & 0 & 1 & 0 & 0 \\
\hline 5 & 0 & 1 & 0 & 0 \\
\hline 6 & 0 & 0 & 1 & 0 \\
\hline $\begin{array}{l}\text { Interval between time of } \\
\text { exposure and time of last call, } \\
\text { min }\end{array}$ & - & - & - & 78 \\
\hline \multicolumn{5}{|l|}{ Percentile } \\
\hline 25th & 30.0 & 21.0 & 62.3 & \\
\hline 50th & 45.0 & 77.2 & 108.7 & \\
\hline 75th & 93.0 & 127.2 & 196.5 & \\
\hline 95th & 216.6 & 265.9 & 1244.3 & \\
\hline
\end{tabular}

regarding young children who accessed ENDS paraphernalia accidentally. There was a weak indication that adolescents might have been the subject of calls more frequently than older children or adults. Apart from usual e-cigarette use, adults most frequently called regarding spills and device malfunctions. Nearly half of those exposed were asymptomatic, and only $8(4.3 \%)$ required assessment at a health care facility.

The spike in ENDS-related exposures may reflect an increase in e-cigarette use, lack of familiarity with new products and/or increased media reports highlighting adverse effects. ${ }^{11,13,31}$ In parallel with this study, the Canadian Hospitals Injury Reporting and Prevention Program, an injury and poisoning surveillance system fed by the emergency departments of 11 pediatric and 8 general hospitals, reported a sixfold increase in unintentional injuries or poisonings related to vaping products between January 2013 and August 2018; ${ }^{32}$ most exposures involved children and adolescents. Minors' ability to legally purchase "nonnicotine" ENDS and novel higher-risk uses such as "dripping" (inhaling e-liquids dropped directly onto heated atomizers) could contribute to higher call volumes among adolescents in Canada. ${ }^{33}$

Our study shows how poison centre data may be used for case-based surveillance. Through the routine collection of information regarding flavours and delivery systems (e.g., single-use e-cigarettes, vape pens, e-pipes), poison centre data could be used to target both product-based and edu- cational interventions. Given the frequency of exposures to ENDS among young children, regulations should aim to minimize harms in this age group. Exposures in toddlers might be prevented through child-resistant packaging, which has been effective in preventing deaths associated with orally administered drugs. ${ }^{34,35}$ Prohibiting flavoured e-cigarettes, particularly candy and fruit flavours, could make products less appealing to children. As children were most frequently exposed at home in the current study, education clarifying the contents of e-juices and emphasizing product storage should be offered.

Moreover, given the influence of body weight on toxic effects, sales of highly concentrated nicotine products should be curtailed. The generally accepted lethal dose of nicotine in an adult is $30-60 \mathrm{mg} \cdot{ }^{36}$ Extrapolation of the median lethal dose to children is debatable but could be estimated as 0.8 $1.0 \mathrm{mg} / \mathrm{kg}$. Given toddlers' low weights, current Canadian proposals to limit the nicotine concentration in e-juices to $66 \mathrm{mg} / \mathrm{mL}$ may be insufficiently protective. ${ }^{37}$ The low prevalence of major adverse effects in the current study may have been due to the small volumes ingested or to lower-thanlabelled nicotine concentrations in ingested products. ${ }^{11}$

Adolescents should be protected through restrictions on sales and advertisements. Young people, who cannot legally buy cigarettes, should also not be permitted to purchase ENDS, including those that are "nicotine-free." In the present study, many people exposed to "low" nicotine or "nicotine-free" solutions still experienced symptoms, consistent with prior studies 
showing that labelled concentrations poorly reflect actual nicotine content. ${ }^{38,39}$ ENDS should also be subject to marketing restrictions that apply to conventional cigarettes.

Exposures in adults should be addressed through improved packaging and manufacturing standards. A small but important number of exposed adults mistook bottled e-juice for another solution such as eyedrops; this might be remedied with clearer labelling or more distinctive packaging. ${ }^{10,13}$ Regulations governing manufacturing, packaging and labelling could also yield more comprehensive data. In our study, the nicotine dosage frequently could not be calculated as product concentrations were not always available.

\section{Limitations}

As our study used BC data, the findings may not be generalizable to other provinces. Exposure identification was limited to exposures that led to a call to the poison centre call, whereas the US National Academy of Medicine estimates that less than half of all poisonings lead to poison centre calls. ${ }^{40}$ Furthermore, poison centre data may underestimate exposures in urban areas, where increased access to services and expertise may decrease reliance on poison centre services. ${ }^{41}$ Our database was not validated against emergency department or other records, or by checking with callers, although a fraction of call records were reviewed and validated by DPIC senior staff. All information was gathered from callers or relevant health care practitioners, and some records contained missing fields. There were variations in coding, and free-text call reports were not standardized. For other fields, there was a default (e.g., the default for place of exposure was "own place of residence"). We mitigated these limitations by validating all fields against verbatim call note information. Lack of follow-up created important limitations in the interpretation of clinical symptoms. Although about half of callers telephoned the poison centre within 10 minutes of the exposure, follow-up was inconsistent. Exposures to e-juices with the highest nicotine concentrations were more likely to be followed. Full clinical trajectories were not recorded and could not be discovered through physician or hospital chart reviews, as patient identifiers were inconsistently noted. This could be addressed through more rigorous follow-up or data linkage.

\section{Conclusion}

The availability of poison centre data presented a timely opportunity to study a rapidly changing, relatively novel exposure through detailed exposure records obtained within minutes to hours of the exposure. British Columbia experienced a sixfold increase in ENDS-related calls to the provincial poison centre between 2012 and 2017, driven by ingestions in young children. Electronic cigarettes are relatively novel, and it is important that both the public and health care providers be aware of potential health effects. Nicotine is the primary known hazard, and the amount of nicotine present in e-juices can exceed the labelled concentrations. Highconcentration products may present a unique hazard to young children given their low body weight. Moreover, e-juice bottles are sometimes mistaken for other substances. Clear, standardized labelling and child-resistant packaging should be required. As rates of exposure are not declining, increased surveillance (including surveillance across multiple poison centres) may elucidate the ongoing epidemiologic features of exposure.

\section{References}

1. Riker CA, Lee K, Darville A, et al. E-cigarettes: Promise or peril? Nurs Clin North Am 2012;47:159-71.

2. Bertholon JF, Becquemin MH, Annesi-Maesano I, et al. Electronic cigarettes: a short review. Respiration 2013;86:433-8.

3. Corsi DJ, Boyle MH, Lear SA, et al. Trends in smoking in Canada from 1950 to 2011: progression of the tobacco epidemic according to socioeconomic status and geography. Cancer Causes Control 2014;25:45-57.

4. Barrington-Trimis JL, Urman R, Leventhal AM, et al. E-cigarettes, cigarettes, and the prevalence of adolescent tobacco use. Pediatrics 2016;138:e20153983.

5. Jamal A, Gentzke A, Hu SS, et al. Tobacco use among middle and high school students - United States, 2011-2016 [published erratum in MMWR Morb Mortal Wkly Rep 2017;66:765]. MMWR Morb Mortal Wkly Rep 2017;66:597-603.

6. Singh T, Arrazola RA, Corey CG, et al. Tobacco use among middle and high school students - United States, 2011-2015. MMWR Morb Mortal Wkly Rep 2016;65:361-7.

7. Hammond D, Reid JL, Cole AG, et al. Electronic cigarette use and smoking initiation among youth: a longitudinal cohort study. CMAf 2017;189: E1328-36.

8. Soneji S, Barrington-Trimis JL, Wills TA, et al. Association between initial use of e-cigarettes and subsequent cigarette smoking among adolescents and young adults: a systematic review and meta-analysis. 7 AMA Pediatr 2017;171:788-97.

9. Forrester MB. Pediatric exposures to electronic cigarettes reported to Texas poison centers. 7 Emerg Med 2015;49:136-42.

10. Weiss D, Tomasallo CD, Meiman JG, et al. Electronic cigarette exposure: Calls to Wisconsin poison control centers, 2010-2015. WMF 2016;115:306-10.

11. Vakkalanka JP, Hardison LS Jr, Holstege CP. Epidemiological trends in electronic cigarette exposures reported to U.S. poison centers. Clin Toxicol (Phila) 2014;52:542-8.

12. Electronic cigarettes and liquid nicotine data. Alexandria (VA): American Association of Poison Control Centers; 2018 Jan. 31). Available: https://aapcc.s3. amazonaws.com/files/library/E-cig_Nicotine_Web_Data_through_1.2018.pdf (accessed 2018 Mar. 25).

13. Chatham-Stephens K, Law R, Taylor E, et al. Exposure calls to U.S. poison centers involving electronic cigarettes and conventional cigarettes - September 2010-December 2014. 7 Med Toxicol 2016;12:350-7.

14. Seo AD, Kim DC, Yu HJ, et al. Accidental ingestion of e-cigarette liquid nicotine in a 15-month-old child: an infant mortality case of nicotine intoxication. Korean 7 Pediatr 2016;59:490-3.

15. Noble MJ, Longstreet B, Hendrickson RG, et al. Unintentional pediatric ingestion of electronic cigarette nicotine refill liquid necessitating intubation. Ann Emerg Med 2017;69:94-7.

16. Marynak KL, Gammon DG, Rogers T, et al. Sales of nicotine-containing electronic cigarette products: United States, 2015. Am 7 Public Health 2017;107:702-5.

17. Davis B, Dang M, Kim J, et al. Nicotine concentrations in electronic cigarette refill and do-it-yourself fluids. Nicotine Tob Res 2015;17:134-41.

18. Kim S, Goniewicz ML, Yu S, et al. Variations in label information and nicotine levels in electronic cigarette refill liquids in South Korea: regulation challenges. Int 7 Environ Res Public Health 2015;12:4859-68.

19. Buettner-Schmidt K, Miller DR, Balasubramanian N. Electronic cigarette refill liquids: child-resistant packaging, nicotine content, and sales to minors. $\mathcal{F}$ Pediatr Nurs 2016;31:373-9.

20. Population estimates. Victoria: British Columbia Ministry of Health; updated June 2019. Available: www2.gov.bc.ca/gov/content/data/statistics/people -population-community/population/population-estimates (accessed 2018 Nov. 25).

21. Census profile, 2016 census. Ottawa: Statistics Canada; 2019. Available: https://www12.statcan.gc.ca/census-recensement/2016/dp-pd/prof/index.cfm? Lang=E (accessed 2019 June 21).

22. Poison information. Vancouver: British Columbia Drug and Poison Information Centre; 2017. Available: www.dpic.org/content/poison-information (accessed 2018 Nov. 15)

23. Yildiz D. Nicotine, its metabolism and an overview of its biological effects. Toxicon 2004:43:619-32.

24. Novotny TE, Hardin SN, Hovda LR, et al. Tobacco and cigarette butt consumption in humans and animals. Tob Control 2011;20(Suppl 1):i17-20.

25. Metz CN, Gregersen PK, Malhotra AK. Metabolism and biochemical effects of nicotine for primary care providers. Med Clin North Am 2004;88:1399-413, ix.

26. Kamboj A, Spiller HA, Casavant MJ, et al. Pediatric exposure to e-cigarettes, nicotine, and tobacco products in the United States. Pediatrics 2016;137: e20160041. 
27. Durmowicz EL. The impact of electronic cigarettes on the paediatric population. Tob Control 2014;23(Suppl 2):ii41-6.

28. Regional health authorities. Victoria: British Columbia Ministry of Health. Available: www2.gov.bc.ca/gov/content/health/about-bc-s-health-care-system/ partners/health-authorities/regional-health-authorities (accessed 2018 Nov. 16).

29. B.C. Health System Strategy Geographic Service Areas. Victoria: British Columbia Ministry of Health; May 2013, updated April 2016. Available: https://www2.gov.bc.ca/assets/gov/health/about-bc-s-health-care-system/ health-priorites/geographic-service-areas.docx (accessed 2019 June 23).

30. National Poison Data System (NPDS) data dictionary. Version 2016.07.11. Alexandria (VA): American Association of Poison Control Centers; 2016.

31. Electronic nicotine delivery systems. Proceedings of the Conference of the Parties to the WHO Framework Convention on Tobacco Control, Sixth Session; 2014 Oct. 13-18; Moscow: Russian Federation. Geneva: World Health Organization; 2014. Available: http://apps.who.int/gb/fctc/PDF/cop6/FCTC_COP6_10Rev1-en. pdf?ua=1 (accessed 2018 Apr. 23).

32. Injuries and poisonings from vaping products including e-cigarettes [data blog]. Ottawa: Public Health Agency of Canada; 2018 Oct. 11. Available: https:// infobase.phac-aspc.gc.ca/datalab/ecigarette-blog-en.html (accessed 2018 Nov. 27).

33. Krishnan-Sarin S, Morean M, Kong G, et al. E-cigarettes and "dripping" among high-school youth. Pediatrics 2017;139:e20163224.

34. Rodgers GB. The effectiveness of child-resistant packaging for aspirin. Arch Pediatr Adolesc Med 2002;156:929-33.

35. Rodgers GB. The safety effects of child-resistant packaging for oral prescription drugs. Two decades of experience. $7 A M A$ 1996;275:1661-5.

36. Mayer B. How much nicotine kills a human? Tracing back the generally accepted lethal dose to dubious self-experiments in the nineteenth century. Arcb Toxicol 2014;88:5-7.

37. Proposals for the regulation of vaping products. Ottawa: Health Canada; 2017 Aug. 31. Available: www.canada.ca/en/health-canada/programs/consultation -regulation-vaping-products/proposals-regulate-vaping-products.html (accessed 2018 Dec. 4).

38. El-Hellani A, El-Hage R, Baalbaki R, et al. Quantification of free-base and protonated nicotine in electronic cigarette liquids and aerosol emissions. Chem Res Toxicol 2015;28:1532-7.
39. Cameron JM, Howell DN, White JR, et al. Variable and potentially fatal amounts of nicotine in e-cigarette nicotine solutions. Tob Control 2014; 23:77-8.

40. Institute of Medicine. Forging a poison prevention and control system. Washington: National Academies Press; 2004:48-75.

41. McLean KE, Henderson SB, Kent D, et al. Calls to the British Columbia Drug and Poison Information Centre: a summary of differences by health service areas. Online 7 Public Health Inform 2014;6:e179.

Affiliations: School of Population and Public Health (Choi, Le, Rose), Faculty of Medicine, University of British Columbia; BC Centre for Disease Control (Rahim, Rose, Kosatsky), Vancouver, BC

Contributors: Alex Choi conceived and designed the study, contributed to the chart review and analysis, interpreted the data, and drafted and revised the manuscript. Megan Le contributed to the chart review, and data analysis and interpretation. Tissa Rahim contributed to data analysis and interpretation, and design of the figures. Caren Rose contributed to the statistical analysis and critically revised the manuscript for important intellectual content. Tom Kosatsky supervised all aspects of the work. All of the authors approved the version to be published and agreed to be accountable for all aspects of the work.

Funding: This research was completed through internal funding at the BC Centre for Disease Control.

Acknowledgements: The authors thank the staff of the BC Drug and Poison Information Centre for contributing to data collection and sharing their experiences, the poison information specialists for their advice on data extraction, and Victoria Wan for accessing and managing the data.

Supplemental information: For reviewer comments and the original submission of this manuscript, please see www.cmajopen.ca/content/7/3/ E462/suppl/DC1. 